\title{
The Application of Salutogenesis in Politics and Public Policy-Making
}

\author{
Ruca Maass, Charlotte Kiland, Geir Arild Espnes, \\ and Monica Lillefjell
}

\section{Introduction}

Politics can loosely be defined as the process of making and executing collective decisions (Hague \& Harrop, 2010, p. 442). Political decisions affect every part of our lives, from the distribution of rights and resources, how institutions are run and which goals we pursue as a society, to regulating even personal relationships and family bonds. Thus, politics is one of the upstream conditions that shape our society and set the direction and the pace for how society is developing.

Salutogenesis is concerned about the relationship between societal conditions and health. According to the salutogenic model, health is created and maintained through repeated experiences with societal conditions (Antonovsky, 1987). Health is described along a continuum, ranging from illhealth to perfect health. An individual's position on this scale is heavily influenced by life experiences, shaped by biological, individual, societal and cultural forces sensitive to politics and policy-making (Antonovsky, 1979, 1987). Within public health, there has been a growing consensus that health is political, and that health issues need to be brought into the political arena to advance population health (Bambra et al., 2005; Kickbusch, 2015; Mackenbach, 2014). This is linked to the health determinants depending on political action. Health is understood as a critical dimension of human rights and citizenship (Bambra et al., 2005). Improving the upstream conditions for health demands to address social

R. Maass $(\bowtie) \cdot$ M. Lillefjell

Department of Neuromedicine and Movement Science, Faculty of Medicine and Health Science, Norwegian University of Science and Technology (NTNU), Trondheim, Norway

e-mail: ruca.e.maass@ntnu.no

C. Kiland

Department of Political Science and Management, Faculty of Social Sciences, University in Agder, Kristiansand, Norway

\section{G. A. Espnes}

Center for Health Promotion Research, Department of Public Health and Nursing, Faculty of Medicine and Health Sciences, Norwegian University of Science and Technology, Trondheim, Norway determinants and how they are shaped and negotiated through political processes (Marmot, 2005).

Within the field of political science and public administration, politics is understood as a continuous struggle for power amongst competing interests (Kickbusch, 2015). This power struggle might occur between and within countries. Politics is also about handling challenges at a societal level. A recent example of the importance of tackling challenges can be found in the Covid-19 pandemic (the Corona crisis); a global, collective threat. The crisis sparked a wave of political reactions, ranging from implementing far-reaching measures limiting people's possibilities and movements to an unpreceded extent, to political leaders denying and even ridiculing the threat. Besides yielding quite different results for the spread of, and the death toll from, the disease, do these variations in political actions also illustrate how competing interests (such as keeping the economy going vs. protecting the population from catching the disease) can hugely influence the outcome of political processes?

In turn, processes, and their interplay with media representations, influence coping at an individual as well as at a community level. On the one hand, trust in authorities and sense of coherence (SOC) emerged as crucial coping resources which reduced the risk of developing mental illness during the Covid-19 pandemic across countries (Généreux, David, O’Sullivan, et al., 2020; Généreux, Roy, O'Sullivan, \& Maltais, 2020). On the other hand, false beliefs, mistrust in authorities, stigma, perceived threat and financial loss raised probabilities of ill mental health (Généreux, Roy, David, et al., 2020).

Simultaneously, regardless of what kind of measures were taken (or not taken) in the respective countries, there was protest. Some people in Germany, for example, protested what they perceived as exaggerated measures that deprived them of human rights. Meanwhile, some people in Brazil and the USA asked for more measures to protect the general public and to prioritise health above economic interest. This illustrates the power struggles inherent in political processes: competing interests need to be considered, and solutions that 
are in accordance with one group's interests might be at odds with other groups. Historically, collective challenges often resulted in conflict and division of societies. However, human history, often told as a recollection of catastrophe and conflict, also holds narratives of growth and hope, which helped to prevail and even evolve societies as well as individuals (Bregman, 2020). Also during the Corona crisis, examples of collective challenges bringing out 'the good' in people could be found: spontaneous acts of kindness and solidarity became visible, from theatre-playing outside of nursing homes to the upspring of neighbourhood help collectives that assisted vulnerable neighbours with shopping and other chores.

Moreover, the implemented measures contributed to speed up developments like digitalisation. In other words, resolving one collective challenge can sometimes fuel a positive development in society. Overcoming and growing with challenges is in line with a salutogenic perspective, and at the heart of the salutogenic process (Antonovsky, 1987; Généreux, Roy, O’Sullivan, \& Maltais, 2020; Namihira, 2019).

This chapter explores if and how salutogenesis can be applied to the field of politics and policy-making. We start by giving a short overview of the field of political science, politics and policies. We then clarify the position of salutogenesis on politics and unravel potential links before we explore how salutogenesis could contribute to understand and inform politics.

\section{Politics and Policies}

Politics, as defined above, is about making collective decisions and negotiate power. Public policy-making relates to the actions of the government and the processes of articulating and matching actors' goals and means into decisions or non-decisions to affect and influence members of a national state or sub-national jurisdiction. Thus, whilst politics refers to the decision-making process, does public policy contribute to translate and implement these decisions into the various domains of societal life.

Within traditional administration, the political context is characterised by bureaucratic structures, separate spheres between politics and administration and a logic of rationaltechnical processes in which public policy-making take place. Those who are involved tend to follow some general procedures (Holmberg \& Rothstein, 2012): (1) agenda setting helping policy-makers decide which problems to address; (2) policy formation where solutions to problems are shaped and argued; (3) policy legitimation to move the policy through a formal decision-making (or legislative) process; (4) policy implementation turning policies into action; (5) policy evaluation to determine if the policies they create are effective in achieving their goals; (6) policies resulting in their maintenance, succession or termination due to policymakers' shifting goals, values, beliefs or priorities.

Critique of the rational-technical logic has underlined that the combination of traditional bureaucracy and interest-group politics led to a 'muddling through' approach (Lindblom, 1979). This resulted in fragmented politics creating 'silos' or 'stovepipes' within organisations (Wilson, 1989). Today, most major public policy problems are 'wicked', that is they are inherently resistant to a clear definition and an agreed solution (Head \& Alford, 2015). As public health problems become more wicked, cutting across administrative levels, sectors and units, political and administrative leaders are challenged.

Since the late 1980s, two public reform waves have influenced the political-administrative system in European governments: that of New Public Management (NPM) and post-New Public Management (post-NPM) (Christensen, 2012; Christensen \& Lægreid, 2007, 2011). NPM ideas focused on improving efficiency, horizontally specialisation of the political-administrative apparatuses, marketisation, private-sector management style, explicit performance standards and strengthened output/outcome control (Hood, 1991, Christensen, 2012, p. 1). Along with the increased need for more 'evidencebased' public policy-making and administrative expertise, this resulted in fragmented knowledge and understanding about factors that might cause or influence complex societal problems. It became difficult to address significant issues comprehensively and challenging to grapple the input and involvement of a broader range of actors in society. Generally, NPM practices have been unsuitable in dealing with complex problems (Christensen \& Lægreid, 2011; Head \& Alford, 2015). As a response to the failure in handling wicked and complex problems, the rise of so-called post- New Public Management ideas in the early 2000s called for more holistic approaches, arguing for whole-of-government approaches and lately whole-of-society approaches (Christensen, 2012; Christensen \& Lægreid, 2007). They seek to improve the horizontal coordination of governmental organisations and to enhance coordination between government and other actors; for example, citizens, civil society actors, voluntary and private actors.

Within the context of representative democracy, processes to strengthen participation and influence between elections might be regarded as disturbing for the public policy-making processes (Østerud 2004). Still, the post-NPM reforms imply the focus of government to have increasingly shifted to horizontal coordination and collaboration. The organisational forms of public administration have become increasingly complex and hybrid (Christensen, 2012). We argue that these post-NPM ideas emphasising involvement and collaboration provide a new angle for the application of a more upstream and salutogenic perspective in public policy-making.

As a result of increased complexity and fragmentation of NPM reforms, there is now a widespread focus on the need for more "collaboration" and "coordination" (Agger \& 
Sørensen, 2018; Christensen, 2012). A commonly held notion is that working across organisational, jurisdictional and political-administrative boundaries will enable more efficient and effective policy development, implementation and service delivery. These ideas address the importance to think broadly about major social problems and possible ways of addressing them. However, collaboration across sectors carries it's own challenges, often rooted in the (politically defined) responsibilities, diverging values, fragmented knowledge and struggles over resources. As such, Head and Alford (2015) argue for new models of leadership that better appreciate the distributed nature of information, interests and power and can address these problems in a coordinated manner.

One challenge emerging from the fragmentation of knowledge and responsibility is that policies are developed to address specific problems, solutions or sectors. Accordingly, policies developed within one sector may fail to address important aspects in other sectors and result in incoherent policies. Policy coherence can be described as 'the systematic promotion of mutually reinforcing policy actions across government departments and agencies creating synergies towards achieving the agreed objectives' (OECD, 2019). Besides aiming to harmonise policies between sectors, policy coherence also touches into matters of implementing policies and ensuring that stakeholders receive the appropriate competence, resources and motivation to translate policies into effective action (Nilsson et al., 2012). Thus, policy coherence emerges as an important aspect in politics and policy-making and can be described horizontally (between sectors) and vertically (across different government levels and from decision-makers to the general public). Experiences of coherent structures have been linked to the ability to make compromises, participating in adapting and creating appropriate resources, and even develop trust in society and its institutions (Habermas, 2016; Kickbusch \& Szabo, 2014; Marmot \& Allen, 2013). Trust in the state and its governance emerged, in turn, as an important coping resource during the early stages of the Corona pandemic (Genereux et al., 2020; Généreux, David, O’Sullivan, et al., 2020; Généreux, Roy, David, et al., 2020). Thus, providing populations with a coherent understanding of what is going on contributes to stabilising society. Additionally, recent research suggests that populations which display more trust in their civic and political leaders are better equipped to handle collective challenges (Généreux et al., 2020; Sagy, 2015; Sagy \& Braun-Lewensohn, 2009).

\section{Linking Salutogenesis and Public Policy-Making}

Salutogenesis aims at being an umbrella for a wide range of positive health and well-being-related concepts such as resilience, coping and quality of life (Lindström \& Eriksson, 2010). Strümpfer (1995) attempted to broaden the term, to also include a general ability to meet hardship. He suggested to 'fortigenesis' (the origin of strength) as a term to include matters and outcomes beyond the health sector. Whilst the term itself did not reach widespread attention in the scientific community, researchers concerned with salutogenesis have increasingly applied salutogenic perspectives on matters beyond the health sector.

According to Antonovsky, the answer to the question 'what makes people healthy?' is 'a strong sense of coherence (SOC)'. The SOC describes an individual's outlook on life, based on individual experiences with societal forces (Antonovsky, 1979, 1987). A strong SOC indicates that the world is perceived as comprehensible, manageable and meaningful. A strong SOC helps to identify and adequately apply resources and to cope with stressors and resolve challenges in a health-promoting manner (Antonovsky, 1987; Maass, 2018).

The SOC is developed through overcoming challenges and the internalisation of resources. Specific resistance resources (SRRs) can be applied to resolve specific challenges. SRR play an important role in individual health promotion. For example, resources to support young families during the first weeks of a new baby's life can be crucial for this specific experience, whilst such specialised resources would not be applicable to resolve a wide range of other challenges.

On the other hand, resources can be internalised and turned into 'generalised resistance resources' (GRR). GRR can be found at any level, from the individual to the societal level, and can be applied flexibly to achieve various outcomes. GRR thereby become part of the individual's SOC. The internalisation of resources is fuelled by 'significant life events', which challenge established coping strategies. Significant life events touch into comprehensibility, manageability and meaningfulness simultaneously (Antonovsky, 1987).

Societal and political matters are thereby intertwined with individual SOC: they facilitate and order our experiences, pose challenges and distribute resources; they define our rights and responsibilities and the social position that again shapes our experiences and expectations. Developing society in a salutogenic direction might benefit populations, individuals and society itself. However, according to Antonovsky, 'no society [yet] (...) managed to avoid structural limitations, or $(\ldots)$ to provide structural access to the goals it has propagated' (Antonovsky, 1979, p.88).

Salutogenesis describes how matters of politics and policies contribute to shaping individual's and group's ability to cope. But how can salutogenesis contribute to outline strategies and structure processes linked to politics and policymaking? According to the above, salutogenesis can be understood and applied unto public policy-making in two distinct ways: as a global orientation towards a positive out- 
look on life, problem-solving and resource-focus; or as a distinct way to organise approaches in line with the more specific relationships between the 'upstream' conditions, resources and the three dimensions of SOC.

\section{Salutogenesis as a Global Orientation Towards Positive Outcomes and Resources}

Applying a salutogenic angle on politics and policy-making implies a focus on resources, possibilities and solutions. As outlined above, policies are often designed to resolve "wicked problems". Besides often leading to isolated and narrow measures, can this approach be described as problem-based. In a way, this mirrors the dominant approach in medicine, pathogenesis, which seeks to identify and isolate 'the cause of suffering' and then remove it. A salutogenic approach, on the other hand, challenges this starting point by posing the salutogenic question: "what makes people healthy?" As an equivalent in political science, one might ask, 'how can we tackle these challenges in a good way, by learning and growing?', or 'how can we create societies that bring out the good in people?'. This implies a focus on the questions 'what works?' and 'why and how does it work?', as starting points for developing policies.

\section{Experiences from Various Settings}

There are some examples of studies applying salutogenesis unto matters outside of the 'health' sector. For example, Kelly (2015) applies the salutogenic question unto the school context, turning the question from "why does it not work?" into "how can it work?", and proposes salutogenesis as a beneficial approach for framing new approaches for school leadership. Brolin et al. (2018) applied salutogenesis to develop a strength-based approach to health in a school. Students developed a narrative in which health was conceptualised as a collective, value-based asset, which implies that students are co-responsible for others' health outcomes. Students were more likely than teachers to include salutogenic factors and apply a value-based health discourse. This was also in contrast to the school health initiative, in which individualistic, pathogenic notions dominated. A similar finding was made by Dell' Olio, Vaandrager, \& Koelen, (2018), who applied salutogenesis unto the specific context of students with disabilities and advocate changes in the academic services for these students. They found that the students were able to assess a number of both specific (such as institutional services and disease information) and generalised resistance resources (including social capital and awareness of one's strengths). Their findings suggest that policy-makers focus more on challenges and obstacles, whilst students themselves described some of these 'obstacles' as opportunities and even assets.

In salutogenesis, stressors and assets are described as 'two sides of the same coin'. Overcoming challenges is described as a salutary process (Antonovsky, 1979, 1987). A salutogenic orientation emphasises the importance of participatory approaches, the world views of stakeholders and target groups and applying empowering and enabling strategies. This turns the focus away from shortcomings which, in the long run, can contribute to further victimisation of vulnerable groups. Engaging in a positive process focused on strength and opportunities might in itself contribute to better health through a shift of focus and by experiences of mastery and learning along the way (Généreux, Roy, O'Sullivan, \& Maltais, 2020). In the above examples, the desired outcome of the interventions is not at the level of individual health. Instead, the focus is on ways to organise the school environment to help students to cope with everyday challenges. They thereby illustrate the importance of organisation and policies to achieve a salutary process for collectives as well as individuals.

Similar findings from the work-sector support these notions. For example, Reid and Quayle (2008) apply a salutogenic perspective on occupational health and propose salutogenesis as a theoretical framework that could contribute to policy development and occupational assessments by bridging work-related and individual factors. Pijpker and colleagues (2019) investigated the role of learning with respect to SOC and GRR. They suggest promoting learning through both formal and informal ways as a mean to strengthen SOC through experiences from working life. Vaandrager and Koelen (2013) define a salutogenic workplace health as 'the ability of the workforce to participate and be productive in a sustained and meaningful way'. They describe a salutogenic organisation as an organisation that provides resources and offers coherent experiences. They advocate a salutogenic orientation to promote motivation and the experience of meaningfulness in the workforce, and to enable the organisation to focus on its strength and develop measures based on what works. Evidence suggests that users, in these cases, students and workers, apply a more salutogenic lens than do leaders and policy-makers, and emphasise structural and collective resources and outcomes above individual ones.

\section{From 'Wicked Problems' to 'Healthy Societies'?}

The above suggests that applying salutogenesis unto politics and policy-making implies to phrase positive goals, and emphasises the interplay between the individual and her supporting structures; society and societal institutions. A more consistent application of salutogenesis might benefit policy 
development in more than one way. To focus on growth and possibilities might in itself contribute to find solutions rather than dwell on challenges. Working together towards common goals might contribute to greater enthusiasm and commitment than working to prevent negative development (Elliot, 1999). It contributes to make possible benefits visible, instead of fostering fear and anxiety about what is to come. For policy-makers and implementers, it represents an opportunity to overcome the role as a 'fire extinguisher' rushing from challenge to challenge and trying to fight each crisis isolated. Instead, focusing on salutogenic solutions and societies might facilitate the development of desirable future scenarios and encourage visionaries to strive for a salutogenic society.

Policy-makers and politicians experience to be confronted with ever-new problems which have to be dealt with here and now to satisfy potential voters. However, this position is unfavourable to address the complexity and wickedness in such societal problems. For example, social inequality can contribute to increased crime, unemployment, drug abuse, raise levels of social conflict, exclusion and discrimination and even result in political instability and distrust. Trying to fight each of these adverse outcomes separately might contribute to diverting attention and effort from the inequality which is at the bottom of all these 'wicked' problems (Marmot, \& Wilkinson, R. (Eds.)., 2005; Marmot \& Allen, 2013).

A salutogenic approach would address these problems with a strategy of cooperative society development. It might thereby apply processes and produce solutions that contribute to level out social inequality. The above examples indicate that users (students and employees) often have a more salutary focus than policy-makers. This supports notions of citizen involvement throughout the whole process of policymaking: identifying shared goals and achieve shared understandings about what is going on is a crucial condition for cooperation. Simultaneously, acknowledging the experiences and aspirations of especially minority groups might be an important first step towards identifying resources and develop strength (Rappaport, 1995).

\section{Politics and Policy Coherence}

In salutogenesis, the origin of health is described as 'a sense of coherence', which is developed based on coherent experiences with the societal structures. Thus, aiming at creating coherent structures emerges as an important aim in politics and policy-making. Two main challenges arise from policyand politics-making processes: cooperation and coherence both horizontally (between sectors and actors) and vertically (top-to-bottom within each sector, from decision-makers over implementers to the public).

\section{Horizontal Coherence: Collaboration and Cooperation}

Horizontal coherence addresses issues that arise from multisectorial collaboration. Collaboration and cooperation across sectors and actors are described as an important mean in respect to negotiating politics: solutions have to be found across spatial domains. However, this goal is challenged by structural elements within NPM, such as the fragmentation of responsibilities, silo-thinking and rigid input/output regimes which crave for effectiveness within each sector (Christensen, 2012; Wilson, 1989).

Collaboration processes thereby often illustrate the root problems within politics: struggles and negotiations about power and influence. Competing interests are not only driven by population groups. Even within public government and administration, conflict of interests arise. In politics, this is expressed by the political parties which are distributed power through an election. They depend upon and are sensitive to changes in public opinion. Within public administration, conflict of interest arises from divergent understandings and knowledge, shortness of staff and funding and the input/output regime, which leads each sector to prioritise their specific goals above common aims. These challenges can easily be described as incoherence, according to Antonovsky's framework: a lack of comprehensibility due to fragmented knowledge, a lack of manageability due to under-funding and time pressure and a lack of meaningfulness if common goals are perceived less important than sector-specific aims. As effectiveness is measured within each sector, contributing to achievements that are measured in other sectors might even be perceived to be contra-productive: if you or your sector cannot make your contributions visible, you might get distributed less resoruces next time budgets are negotiated.

To what extent the approaches of post-NPM endorse solutions to these common problems remains unknown. PostNPM approaches build on extensive collaboration and imply a certain degree of citizen involvement (Christensen, 2012; Østerud, 2004). Instead of delegating power to market actors, cooperation with the third sector and involvement of civil society actors are at the forefront. However, solely emphasising the need for more collaboration is not enough, and might even be counter-productive, if it is perceived as yet another aim to live up to, without being equipped with the means to do so. To take a whole-of-government or even whole-ofsociety-approach seriously, it seems important that the aims of the approach indeed are rooted, and acknowledged as valid, by the whole of government/society (Kickbusch \& Szabo, 2014). Likewise, common goals should be accompanied by a sound distribution of responsibilities and resources.

All in all, these notions emphasise the importance of establishing shared understandings and common goals across sectors. Such goals need to be phrased and incorpo- 
rated into common both common strategic plans to ensure that they are perceived as valid across sectors. On an international level, the sustainable development goals (SDG) represent such common goals (UN, 2017). However, such overarching goals can sometimes be unclear, and stakeholders might lack insights about how they can address them within their sector and from their position. Thus, overarching goals should be translated into the various sectors, to ensure that all stakeholders have the motivation and the means to work towards the overarching, common goal within their field of responsibility. To achieve horizontal coherence, it seems crucial to a) ensure a shared understanding about what is going on, as well as increase understanding about the roles and responsibilities the different stakeholders can take in this regard; b) ensure that all involved stakeholders have the means and resources to take their responsibility and contribute to the common goal; and c) ensure that all stakeholders have the motivation to engage in working towards common goals, that is, by translating these goals into the sector-specific strategic plans and make the contributions of each sector visible throughout the process. Keeping an eye on these factors throughout decision-making and implementation might proof a beneficial way to establish and maintain coherence throughout the political process. Preferably, both the common aims that are established and the means applied to achieve them should be rooted in the population, which, according to the above, often phrases more salutogenic aims than professionals (Dell' Olio, Vaandrager, \& Koelen, 2018; Reid \& Quayle, 2008). Thus, besides horizontal collaboration, user involvement and participatory approaches emerge as important tools to achieve vertical coherence in politics.

\section{Vertical Policy Coherence: From a Decision to Implementation}

Vertical coherence in politics is about making decisions and implementing them in a way which adds to comprehensibility, manageability and meaningfulness for the targeted population. Here, the importance of policies and implementation processes emerges: often, valid goals can be translated into measures which are contradictive, add to the burden or are perceived as incoherent by those that are meant to be supported (Nilsson et al., 2012).

If policies are perceived as posing challenges without addressing the means to resolve these challenges, or if they are perceived as meaningless - or even a threat to what is perceived as meaningful - this might result in distrust towards decision-makers and their representatives (Genereux et al., 2020; Habermas, 2016; Marmot \& Allen, 2013). Consequently, distrust and incoherence can result in destabilised societies, with fragmented sub-groups, and high levels of polarisation and conflict (Yeo, \& Green, M. N. (Eds.).,
2017). During the past decade, we have seen a rise in 'fake news', conspiracy theories, decreasing trust in politicians and increasing polarisation in society, which, in its most extreme outcome, even can foster terrorism and violence. Could the root cause of this be collective experiences of incoherence with the political structures?

The SOC is built through accumulated experiences with coherent, societal structures. However, not only personal but also collective experiences can influence our perceptions and expectations. These are passed down to us across generations and communicated through cultural and social institutions and channels such as stories, movies and the educational system. However, members of different social groups can make profoundly different experiences with the same societal structures (Antonovsky, 1987; Rappaport, 1995). Thus, how society works for you also depends on matters of identity, status and group-belonging.

This also implies that members of minority groups sometimes experience that their expectations, developed through popular culture and learned values, are not met in real-life encounters with the resource. A recent example of this can be found in the "Black Lives Matter (BLM)" - demonstrations against police violence in the USA. They clearly illustrate that one of society's most crucial assets - the institution enforcing law and order and protecting citizens - is experienced more like a risk and a threat by large proportions of the population (Peck, 2015). Other examples include expectations of 'freedom of religion', but being met with ridicule and hatred based on religious clothing (i.e. Slettholm \& Stokke, 2015), or expecting equal opportunities, but then experience geographical, ethnical or gender-based injustice that deprives people of crucial opportunities (Michelsen et al., 2017). Maass et al. (2014) suggest that members of minority groups experience this also in less-prominent contexts. Members of minority groups often experience incoherence regarding policies and their implementation. Such incoherence is reinforced by victim blaming, which fails to acknowledge the structural causes of social injustice (Marmot, 2004; Pascoe \& Smart Richman, 2009; Rappaport, 1995). Examples can be seen in attempts to discredit the victims of police violence sparking the recent BLM protests, to distribute them (part of the) blame for their fate (compare, i.e. Jangar, 2020).

Incoherent experiences are, according to salutogenesis, characterised by a lack of comprehensibility, manageability and/or meaningfulness. Incoherent experiences result from repeatedly hearing that what you know about the world is not valid, realising that you cannot obtain the means to achieve your valid aspirations, discovering that a re-distribution of resources does not accompany promises of a better future or realising that your life lacks meaningfulness. Besides posing a risk for health and wellbeing, this can lead to feelings of alienation and powerlessness. For cultural or value-based 
groups, this can lead to diverging understandings, alienation and even open opposition to existing structures. A state of incoherence is in itself stressful, and individuals and groups will make efforts to re-establish coherence (Antonovsky, 1987).

Sharing experiences with your in-group can be a conscious-rising, empowering experience, which helps you to understand the structural components of your experience, and collectively seek solutions (Carr, 2003). The community emerges as an important coping resource in the face of disaster or conflict (Braun-Lewensohn et al., 2019; BraunLewensohn \& Sagy, 2011; Braun-Lewensohn \& Sagy, 2014; Généreux, David, O’Sullivan, et al., 2020; Généreux, Roy, David, et al., 2020; Généreux, Roy, O’Sullivan, \& Maltais, 2020; Namihira, 2019). The community, and even national states, are crucial contexts for the experience of coherence in difficult times (Sagy et al., 2020; Sagy \& Braun-Lewensohn, 2009; Sagy, 2015; Braun-Lewensohn et al., 2019; Ben David et al., 2017). Research in a European refugee camp suggests that individual and community SOC, together with time spent in the camp and appraisal of danger, explained more than half of the prevalence of anxiety (56\%), depression (53\%) and somatisation (58\%) (Braun-Lewensohn et al., 2019).

On the other hand, individuals with a strong sense of community and national coherence (SOCC/SONC) are often also less open for out-group members, their experiences and interpretations (Mana et al., 2015; Mana et al., 2019; Ben David et al., 2017). A strong national sense of coherence affects willingness to reconcile and acceptance of out-group narratives negatively (Mana et al., 2019). Individuals with strong perceptions of community coherence are also found to be more supportive of separatist strategies and less supportive of integration strategies (Mana et al., 2015). This suggests that whilst the community can be an important coping resource, a strong emphasis on the community might worsen inter-group relations and contribute to shutting out other impulses and explanations. Thus, in-groups that contribute to re-establish coherence in a complex world can quickly develop into so-called echo chambers, in which onesided information is endorsed, and challenging information is dismissed.

In this context, one might wonder if fake news and conspiracies are an expression of this quest for coherence. The struggle about 'the truth' has had a significant impact on political and social development in recent years and highlights the important role of the media concerning politics. Conspiracy theories are not a new phenomenon; however, in the last decade, they gained importance, partly because of social media. Social media are a crucial arena for people to come into touch with and can spread conspiracy theories to a greater audience. Moreover, due to the way social media work, beginning tendencies to get involved with conspiracies might be reinforced, as users are exposed to content similar to the content they engaged with earlier (Jones, 2016). However, also users themselves seek out information which reinforces, rather than challenges their beliefs. Especially consumers of right-wing populist news seem to have tendencies to shut out other impulses (Michelsen et al., 2017). In the long run, being exposed to one-sided information might result in a picture of the world that is only valid in socially confined spaces, where conflicting information is increasingly avoided or discredited (Jones, 2016). Achieved "coherence" would be built strictly on the in-groups world view, and new information has to be shut out or re-defined to fit the already established 'truth'.

Interestingly, Antonovsky describes a phenomenon he called 'fake' or 'rigid SOC'. A rigid SOC is characterised by high scores on all three dimensions but builds on a few specific strategies. Fake-SOC individuals display strong beliefs that they have found answers to 'everything', but these answers would continuously be challenged through everyday experiences involving the wider society (Antonovsky, 1987). Withdrawing into spaces that offer seemingly coherent explanations - such as so-called echo chambers on social media, distinct cultural sub-groups or even closed religious minorities - might seem beneficial in the short run. It can, however, damage SOC by spoiling for real comprehensiveness and flexible strategies (Antonovsky, 1987; Jones, 2016).

On a societal level, alternative explanations in various sub-groups can contribute to polarisation and distrust not only of officials but also other members of society (Mana et al., 2019; Mana et al., 2015; Ben David et al., 2017). To add to this notion, withdrawal into homogenous, deriving sub-groups often happens at the expense of a salutogenic lifestyle. Narratives from people that have been 'radicalised' indicate that the acceptance of the deviant world often is paired with a loss of relationships, of socially valued activities, and loss of meaningfulness. However, this influence might go both ways: accepting a 'new' explanation about society can lead to distrust and conflict in established relationships; or experiencing that relationships do not hold what they promised can lead to seeking acceptance and a new ingroup elsewhere (Löf, 2018). Likewise, believing that the world is governed in secret by an all-powerful group of people (or reptiles) might damage for the experience of meaningfulness (after all, what's the point in trying if everything you do is orchestrated by 'the enemy'?). Simultaneously, gaining access to a group with information and a deeper understanding about 'what is really going on' might contribute to meaningfulness and purpose (after all, nothing better than being part of the exclusive groups battling the ultimate bad guys).

Increased political polarisation is a challenge for the development of a salutogenic society. For example, the importance of meaning-making dialogue to achieve shared 
understandings has been pointed out (Maass et al., 2017). Sharing experiences with out-group members can help to generalise resources beyond personal experiences and thereby gain a more coherent picture of how society works for everyone (Maass, 2018). Somewhat disappointingly have social media not contributed to this kind of dialogue. On the contrary, Internet debates are more likely to reinforce prior held beliefs than challenging them, thereby adding to simplified pictures of society and increasing polarisation (Bolsover, 2020). Combined with diverging values amongst sub-groups, finding common ground and a set of common goals for collaboration might prove difficult.

Thus, increased polarisation might even spoil for involvement and participatory processes, which were established to increase vertical coherence in the first place. Involvement and broad participation have become popular, and often even mandatory tools in policy development (Christensen, 2012). Participatory approaches seem to be compatible with the guiding values of western society, such as democracy and equality. On the other hand, participatory approaches that aim at fulfilling obligations rather than fostering real involvement are common. Notions of 'inclusive processes' can be utilised to defend and validate measures that do not really benefit those in question (Buanes et al., 2004).

Moreover, well-off people are more inclined to grasp chances for involvement and are better at making themselves heard than more deprived groups. Thus, participatory processes can even contribute to social inequality by reinforcing the majorities' world view at the expense of minorities (Buanes et al., 2004). If policies are developed through seemingly inclusive approaches, but in reality, dismiss the experiences of deprived groups, incoherence between expectations towards and experiences with the political processes itself emerges. Such experiences can be generalised unto the society as such and contribute to distrust and contempt towards politicians and political decisions.

\section{Concluding Remarks}

All in all, the picture emerges that salutogenesis can contribute to politics and policy-making by providing a framework that allows to take a step back from immediate, and often pressing, problems and establish a focus on positive outcomes, learning processes and opportunities. Political processes are often characterised by being evidence-based, with a strong emphasis on results and outcomes. Political representatives are concerned with the (short-time) effects of interventions, the "outputs" of politics. On the other hand, applying salutogenic approaches demands long-term and visionary strategies to meet complex challenges. One major challenge in this respect is that knowledge about cause and effectiveness of such appraoches is scarce, and long-time consequences of policies are hard to measure. However, we argue that recent developments, characterised by post-NPM and whole-of-governance approaches, highlight the need for a salutogenic perspective within politics and policy development. A salutogenic society can in this context be described as a society which phrases positive goals rooted in shared understandings about challenges and desirable outcomes. This might equip individuals, groups and stakeholders with necessary resources to resolve challenges and take part in decision-making from every position in society. A salutogenic society facilitates coherent experiences amongst its members and equips them with the necessary skills and resources to become active agents in their own life.

Salutogenesis can contribute to unravel the various influences on the processes of politics and policy-making and help to establish and maintain policy coherence, both vertically and horizontally. The framework of comprehensibility, manageability and meaningfulness might contribute to coherent processes as well as outcomes. 'Comprehensibility' highlights the importance of shared understandings, consistent messages and opportunities for inter-group dialogue. 'Manageability' emphasises the importance of distribution and design of resources in line with responsibilities and burdens, including the rights and the means to pursue one's goals. 'Meaningfulness' implies to apply inclusive strategies and ensure involvement of stakeholders. For multi-sector collaboration processes, linking specific and overarching goals could add meaningfulness and increase motivation to engage in common efforts across sectors.

\section{References}

Agger, A., \& Sørensen, E. (2018). Managing collaborative innovation in public bureaucracies. Planning Theory, 17(1), 53-73.

Antonovsky, A. (1979). Stress, health and coping. New perspectives on mental and physical Well-being. Jossey-Bass.

Antonovsky, A. (1987). Unraveling the mystery of health. Jossey-Bass.

Bambra, C., Fox, D., \& Scott-Samuel, A. (2005). Towards a politics of health promotion. Health Promotion International, 20, 87-93.

Ben David, Y., Hameiri, B., Benheim, S., Leshem, B., Sarid, A., Sternberg, M., ... Sagy, S. (2017). Exploring ourselves within intergroup conflict: The role of intragroup dialogue in promoting acceptance of collective narratives and willingness toward reconciliation. Peace and Conflict: Journal of Peace Psychology, 23(3), 269.

Bolsover, G. (2020). Black Lives Matter discourse on US social media during COVID: polarised positions enacted in a new event. arXiv preprint arXiv:2009.03619

Braun-Lewensohn, O., Abu-Kaf, S., \& Al-Said, K. (2019). Women in refugee camps: Which coping resources help them to adapt? International Journal of Environmental Research and Public Health, 16(20), 3990.

Braun-Lewensohn, O., \& Sagy, S. (2011). Coping resources as explanatory factors of stress reactions during missile attacks: Comparing 
Jewish and Arab adolescents in Israel. Community Mental Health Journal, 47(3), 300-310.

Braun-Lewensohn, O., \& Sagy, S. (2014). Community resilience and sense of coherence as protective factors in explaining stress reactions: Comparing cities and rural communities during missiles attacks. Community Mental Health Journal, 50(2), 229-234.

Bregman, R. (2020). Humankind: A hopeful history. Bloomsbury Publishing PLC.

Brolin, M., Quennerstedt, M., Maivorsdotter, N., \& Casey, A. (2018). A salutogenic strengths-based approach in practice-an illustration from a school in Sweden. Curriculum studies in health and physical education, 9(3), 237-252.

Buanes, A., Jentoft, S., Karlsen, G. R., Maurstad, A., \& Søreng, S. (2004). In whose interest? An exploratory analysis of stakeholders in Norwegian coastal zone planning. Ocean \& Coastal Management, 47(5-6), 207-223.

Carr, E. S. (2003). Rethinking empowerment theory using a feminist lens: The importance of process. Affilia, 18(1), 8-20.

Christensen, T. (2012). Post-NPM and changing public governance. Meiji Journal of Political Science and Economics, 1(1), 1-11.

Christensen, T. \& Lægreid, P. (2007). The whole-of-government approach to public sector reform. Public Administration Review, (November/December), 1059-1066.

Christensen, T., \& Lægreid, P. (2011). Complexity and hybrid public administration - Theoretical and empirical challenges. Public Organization Review, 11(4), 407-423.

Dell' Olio, M., Vaandrager, L., \& Koelen, M. (2018). Applying Salutogenesis to the experiences of students with disabilities in the Netherlands. Journal of Postsecondary Education and Disability, 31(1), 75-89.

Elliot, A. J. (1999). Approach and avoidance motivation and achievement goals. Educational Psychologist, 34(3), 169-189.

Généreux et al. (2020). One virus, four continents, eight countries: an interdisciplinary and international study on the psychosocial impacts of the COVID-19 pandemic among adults. Submitted to the Lancet.

Généreux, G., David, M.D., O'Sullivan, T., Carignan, M.E., BlouinGenest, G., Champagne-Poirier, O., Champagne, E., Burlone, N., Qadar, Z., Herbosa, T., Hung, K., Ribeiro-Alves, G., Arruda, H., Michel, P., Law, R., Poirier, A., Murray, V., Chan, E., \& Roy, M. (2020). Communication strategies and media discourses in the age of COVID-19: An urgent need for action. Submitted to Health Promotion International.

Généreux, M., Roy, M., David, M.D., Carignan, M.E., Qadar, Z., Blouin-Genest, G., \& Champagne-Poirier, O. (2020). Psychological response to the COVID-19 pandemic in Canada: Main stressors and assets. Submitted to Global Health Promotion.

Généreux, M., Roy, M., O’Sullivan, T., \& Maltais, D. (2020). A salutogenic approach to disaster recovery: The case of the Lac-Mégantic rail disaster. International Journal of Environmental Research and Public Health, 17(5), 1463.

Habermas, J. (2016). For a democratic polarisation: How to pull the ground from under right-wing populism. Social Europe 17/11/2016. Retrieved 10/08/2017 from https://www.socialeurope. eu/democratic-polarisation-pull-ground-right-wing-populism.

Hague, R., \& Harrop, M. (2010). Comparative government and politics. An introduction (8th ed.). Palgrave Macmillan.

Head, B. W., \& Alford, J. (2015). Wicked problems: Implications for public policy and management. Administration \& Society, 47(6), 711-739.

Holmberg, S., \& Rothstein, B. (Eds.). (2012). Good governance. Cheltenham.

Hood, C. (1991). A public management for all seasons? Public Administration, 69, 3-19.
Jangar, S. (2020). Georg Floyd criminal past record/arrest history/career timeline: Baggie, gun pregnant and all details. The Courier Daily.

Jones, A. (2016). Talking to ourselves? Political debate online and the echo-chamber effect. Demos.

Kelly, A. (2015). Introducing the concept of salutogenesis to school leadership research: Problematising empirical methodologies and findings. International Journal of Leadership in Education, 18(2), 167-177.

Kickbusch, I. (2015). The political determinants of health-10 years on. BMJ, 350, h81. https://doi.org/10.1136/bmj.h81

Kickbusch, I., \& Szabo, M. M. C. (2014). A new governance space for health. Global Health Action, 7(1), 23507.

Lindblom, C. E. (1979). Still muddling, not yet through. Public Administration Review, 39, 517-526.

Lindström, B., \& Eriksson, M. (2010). The hitchhiker's guide to salutogenesis. Salutogenic pathways to health promotion.

Löf, S. (2018). Radicalisation and de-radicalisation in Finland-support needs in de-radicalisation process. Diaconia University of Applied Science.

Maass, R., Lindstrøm, B., \& Lillefjell, M. (2014). Exploring the relationship between perceptions of Neighbourhoodresources, sense of coherence and health for different groups in a Norwegian neighbourhood. Journal of Public Health Research, 3(1).

Maass, R., Lindström, B., \& Lillefjell, M. (2017). Neighborhoodresources for the development of a strong SOC and the importance of understanding why and how resources work: A grounded theory approach. BMC Public Health, 17(1), 1-13.

Maass, R. E. K. (2018). The neighborhood as a salutogenic setting: How can Salutogenesis contribute to the development of strategies for promoting health and strengthening SOC through a focus on neighborhood-resources? Doctoral thesis, NTNU.

Mackenbach, J. P. (2014). Political determinants of health. European Journal of Public Health, 24(1), 2.

Mana, A., Sagy, S., Srour, A., \& Mjally-Knani, S. (2015). On both sides of the fence: Perceptions of collective narratives and identity strategies among Palestinians in Israel and in the West Bank. Mind \& Society, 14(1), 57-83.

Mana, A., Srour, A., \& Sagy, S. (2019). A sense of national coherence and openness to the "other's" collective narrative: The case of the Israeli-Palestinian conflict. Peace and Conflict: Journal of Peace Psychology, 25(3), 226.

Marmot, M. (2004). Status syndrome. Significance, 1(4), 150-154.

Marmot, M., \& Allen, J. (2013). Prioritising health equity. In K. Leppo, E. Ollila, S. Pena, M. Wismar, \& S. Cook (Eds.), Health in all policies-seizing opportunities, implementing policies. Sosiaali-ja terveysministeriö.

Marmot, M. (2005). Social determinants of health inequalities. The lancet, 365(9464), 1099-1104.

Marmot, M., \& Wilkinson, R. (Eds.). (2005). Social determinants of health. OUP Oxford.

Michelsen, D., Przybilla-Voss, M., \& Luehrmann, M. (2017). Rechtsextremismus und Fremdenfeindlichkeit in Ostdeutschland. Goettinger Institut fuer Demokratieforschung.

Namihira, E. (2019). 'Salutogenesis' and the factors in natural disaster recovery: An essay of preventive measures to health damages caused by natural disaster. Journal of the National Institute of Public Health, 68(4).

Nilsson, M., Zamparutti, T., Petersen, J. E., Nykvist, B., Rudberg, P., \& McGuinn, J. (2012). Understanding policy coherence: Analytical framework and examples of sector-environment policy interactions in the EU. Environmental Policy and Governance, 22(6), 395-423.

OECD, 2019. Policy coherence for sustainable development. Retrieved 20/08/21 from: https://www.oecd.org/gov/pcsd/\#: :text=The\%20 
OECD\%20Recommendation\%20on\%20Policy\%20Coherence $\% 20$ for $\% 20$ Sustainable,environmental $\% 20$ goals $\% 2$ C $\% 20$ and $\% 20$ accelerate\%20progress \%20towards\%20the\%20SDGs.

Østerud, Ø., Engelstad, F., \& Selle, P. (2004). Makten og demokratiet. Gyldendal akademisk.

Pascoe, E. A., \& Smart Richman, L. (2009). Perceived discrimination and health: A meta-analytic review. Psychological Bulletin, 135(4), 531.

Peck, J. H. (2015). Minority perceptions of the police: A state-of-theart review. Policing: An International Journal Of Police Strategies \& Management.

Rappaport, J. (1995). Empowerment meets narrative: Listening to stories and creating settings. American Journal of Community Psychology, 23(5), 795-807.

Reid, T., \& Quayle, E. (2008). A salutogenic perspective on occupational health. The Irish Journal of Psychology, 29(1-2), 35-44.

Sagy, et al. (2020). Salutogenesis and Corona. Work in progress, read more at https://www.stars-society.org/coronaresearchcollab.

Sagy, S. (2015). Coping, conflict and culture: The salutogenic approach in the study of resiliency. Resiliency: Enhancing Coping with Crisis and Terrorism, $41-48$.
Sagy, S., \& Braun-Lewensohn, O. (2009). Adolescents under rocket fire: When are coping resources significant in reducing emotional distress? Global Health Promotion, 16(4), 5-15.

Slettholm, A., Stokke, O. (2015). Politiet: -Kvinner i hijab kan være spesielt utsatt for hatvold. Aftenposten online, 08.08.2015, retrieved 06/12/2017 from https://www.aftenposten.no/norge/i/gE8A/ Politiet\%2D\%2D-Kvinner-i-hijab-kan-vare-spesielt-utsatt-for-hatvold.

Strümpfer, D. J. W. (1995). The origins of health and strength: From 'salutogenesis' to 'fortigenesis'. South African Journal of Psychology, 25(2), 81-89.

UN. (2017). Sustainable development goals. Retrieved 04/10/2020 from: https://sdgs.un.org/goals.

Vaandrager, L., \& Koelen, M. (2013). Salutogenesis in the workplace: Building general resistance resources and sense of coherence. In Salutogenic organisations and change (pp. 77-89). Springer. WHO; 1946. Definition of health.

Wilson, J. (1989). Bureaucracy: What government agencies do and why they do it. NY, Basic Books.

Yeo, A. I., \& Green, M. N. (Eds.). (2017). Living in an age of mistrust: An interdisciplinary study of declining trust and how to get it back. Routledge.

Open Access This chapter is licensed under the terms of the Creative Commons Attribution 4.0 International License (http://creativecommons. org/licenses/by/4.0/), which permits use, sharing, adaptation, distribution and reproduction in any medium or format, as long as you give appropriate credit to the original author(s) and the source, provide a link to the Creative Commons license and indicate if changes were made.

The images or other third party material in this chapter are included in the chapter's Creative Commons license, unless indicated otherwise in a credit line to the material. If material is not included in the chapter's Creative Commons license and your intended use is not permitted by statutory regulation or exceeds the permitted use, you will need to obtain permission directly from the copyright holder. 